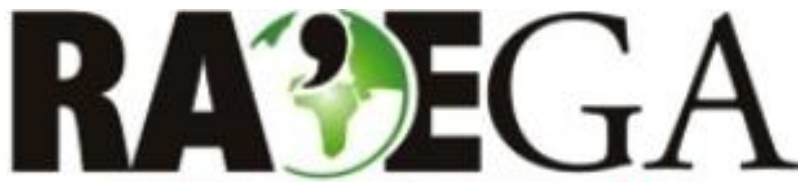

O ESPACYO GEOGRAFICO EM ANÁLISE

\title{
DESASTRES NATURAIS VEICULADOS PELA MÍDIA: ANÁLISE DE CONTEÚDO DAS NOTÍCIAS DO JORNAL DIÁRIO DE GUARAPUAVA
}

\author{
NATURAL DISASTERS THROUGH THE MEDIA: CONTENT \\ ANALYSIS ABOUT THE NEWS FROM DIÁRIO DE GUARAPUAVA \\ NEWSPAPER
}

Danny Jessé Falkembach Nascimento
Técnico em Assuntos Universitários na Universidade Estadual do Centro-Oeste (UNICENTRO)
Coordenadoria de Comunicação Social
Guarapuáva, PR
e-mail: djesse.unicentro@gmail.com

Marquiana de Freitas Vilas Boas Gomes Professora da Universidade Estadual do Centro-Oeste (UNICENTRO)

Departamento de Geografia Guarapuáva, $P R$

Recebido em: 10/04/2013

e-mail:marquiana@gmail.com

\section{Resumo}

Os desastres naturais são eventos extremos em locais onde se concentram seres humanos, gerando impactos socioeconômicos significativos por suas consequências ambientais, e estão cada vez mais presentes na mídia. Porém, nem sempre os veículos de comunicação esclarecem o tema com propriedade. Com o objetivo de problematizar esta questão, neste artigo são apresentadas análises de matérias jornalísticas divulgadas sobre eventos decorrentes das enchentes, inundações e alagamentos na cidade Guarapuava-PR. Utilizou-se como metodologia a análise de conteúdo de sete notícias veiculadas pelo Jornal Diário de Guarapuava, dos anos de 2000, 2005 e 2012. Para isso, considerou-se o recorte temático a nível semântico, por meio da seleção dos enunciados e verificação dos núcleos de sentido que compõem a comunicação. Concentrou-se na identificação da explicação das causas e consequências dos eventos divulgados nos jornais, das fontes responsáveis pelo conteúdo das matérias (atores sociais) e o direcionamento das palavras (positivas e/ou negativas). Dentre os resultados da análise, destaca-se o fato da mídia atuar na popularização do debate sobre os problemas ambientais, porém, sendo pouco eficiente na divulgação de suas implicações. Neste estudo, verificou-se que as explicações nos jornais apresentam equívocos conceituais sobre alagamento, inundação e enchente, além de naturalizarem estes processos, facultando ao leitor a 
possibilidade de compreender a multidimensionalidade imbricada na origem e consequências dos desastres naturais deles decorrentes.

Palavras-chave: Jornal impresso, espetacularização, meio ambiente.

\begin{abstract}
Natural disasters are extreme events in places where is concentrated human beings, generating meaningful socioeconomic impacts due to environmental consequences, and are even more presentes in the media press. However, not even always the media make clear the theme with great importance. Aiming to discuss this matter, are introduced in this paper analysis about journalistics reports published about overflow, flooding and waterlogging in Guarapuava-PR. It was used as methodology the content analysis from seven news disseminated through Diário de Guarapuava Newspaper, about the years 2000, 2005 and 2012. For this purpose it was regarded the thematic focus to semantic level, through the selection of the statements and the core's sense verification which compose the communication. It was concentrated in the explanation's identification of causes and consequences of the published events in the newspapers, of responsible sources about the contents of the subjects (social actors) and the direction of words (positive and/or negatives). Among the analysis results, it is emphasized the fact about the press action in the populatization of the debate about environmental problems, but being little efficient in the dissemination of its implications. In this study, it was verified that the explanations in the newspapers present conceptual misconceptions about waterlogging, flooding and overflow, besides neutralizing these processes, providing the reader the possibilty to understand the multidimensionality existent in the origin and consequences about the arising natural disasters.
\end{abstract}

Keywords: Printed newspaper, spetacularization, environment.

\title{
INTRODUÇÃO
}

Os desastres naturais são eventos extremos em locais onde se concentram seres humanos, gerando impactos socioeconômicos significativos por suas consequências ambientais.

Estes eventos integram um conjunto de fenômenos que afetam diretamente a população. Em 2013, o Ministério da Integração Nacional, publicou o ํㅡㄹ Anuário Brasileiro de Desastres Naturais. Neste, registrou-se a ocorrência de 376 desastres naturais no ano de 2012, os quais causaram 93 óbitos e afetaram 16.977.614 milhões de pessoas, em um total de 3.781 mil municípios (BRASIL, 2012).

No anuário foram classificados 11 tipos de eventos (Seca/Estiagem, Incêndio Florestal, Movimentos de massa, Erosão, Alagamentos, Enxurradas, Inundações, Geadas, Granizo, Tornados e Vendaval), sendo a seca e estiagem o 
DESASTRES NATURAIS VEICULADOS PELA MÍDIA: ANÁLISE DE CONTEÚDO DAS NOTÍCIAS DO JORNAL DIÁRIO DE GUARAPUAVA

evento que mais comprometeu a população $65,06 \%$, seguido dos alagamentos, enxurradas, inundações e vendavais, que somados, atingiram $27,27 \%$ da população. Os demais eventos atingiram conjuntamente $7,67 \%$ da população (BRASIL, 2012).

Destes, interessa neste trabalho aqueles decorrentes da combinação de processos climáticos e hidrológicos. Os desastres naturais decorrentes dos alagamentos resultam da combinação de chuvas intensas com sistemas de drenagem ineficientes, enquanto, no caso das enxurradas, resultam do escoamento superficial de alta velocidade e energia, e, neste caso, os processos podem ser agravados por processos de impermeabilização do solo ocasionada pela urbanização desordenada. Já, os desastres provenientes da inundação são provocados por chuvas prolongadas em áreas mais planas e nos fundos de vale (Brasil, 2012). De modo geral, a combinação de processos climáticos e hidrológicos com a ocupação antrópica em áreas de vulnerabilidade ambiental ampliam as consequências dos desastres ambientais.

$\mathrm{Na}$ Geografia, a abordagem das catástrofes naturais é objeto de preocupação da Geografia Física que por meio de diferentes pesquisas, colabora na compreensão da dinâmica dos processos hidro geomorfológicos e climáticos aos quais potencializam tais eventos. Também é relevante, considerando a dimensão ambiental imbricada nos desastres, à busca por considerar à dinâmica da sociedade na explicação destes processos, sobretudo, porque a intensificação deles é potencializada pela ação antrópica.

Na mesma direção é cada vez mais importante discutir o papel da formação crítica do cidadão sobre o meio ambiente, na qual a sociedade deve ocupar um papel de sujeito produto/produtor dos processos e, não apenas, como vítima destes, principalmente, quando se sabe que algumas catástrofes naturais anunciadas podem ser evitadas, se medidas de prevenção forem adotadas.

Neste aspecto, o processo informativo e educativo sobre os desastres é uma tarefa importante e já tem sido realizado por várias instituições e apropriado pela mídia.

Quanto aos desastres, a mídia tem ocupado um espaço significativo na sua divulgação. Ela é uma importante formadora de opinião para a população em geral, 
DESASTRES NATURAIS VEICULADOS PELA MÍDIA: ANÁLISE DE CONTEÚDO DAS NOTÍCIAS DO JORNAL DIÁRIO DE GUARAPUAVA

seja por disponibilizar a informação em diferentes meios, televisão, rádio, internet, jornal impresso, seja pelo escopo do seu alcance.

O jornal impresso é uma destas mídias. Ele integra texto e imagem, registrando fatos e trazendo explicações, geralmente com mais dados do que o rádio ou a televisão. Isso acontece porque o jornalismo impresso não trabalha com a necessidade da instantaneidade, como outros meios de comunicação. Contudo, como sua preocupação nem sempre é com a formação crítica, não é difícil que a espetacularização da notícia ganhe mais espaço do que o aprofundamento das informações nas matérias jornalísticas.

Outro ponto a considerar é que os jornais, de forma geral, também tem influência nas escolas, e suas informações têm sido utilizadas como recurso pedagógico. No caso dos desastres naturais, o professor pode partir de uma notícia de um jornal para abordar esta questão em sala de aula. Cabe saber se o conteúdo e o esclarecimento do processo estão apresentados com propriedade.

Desta forma, analisar o conteúdo dos jornais quanto aos desastres naturais é uma contribuição no sentido de identificar como este meio de comunicação de massa pode ao invés de contribuir para a educação geográfica e ambiental, banalizar os desastres naturais e/ou confundir o leitor.

$\mathrm{E}$, nesse contexto, este trabalho visa analisar a abordagem dos desastres naturais no jornal impresso, buscando, na análise do seu conteúdo, identificar o discurso midiático, com vistas a problematizar a contribuição da mídia no esclarecimento destes eventos.

Para isso, analisa sete notícias sobre as enchentes, inundações e alagamentos, eventos ocorridos na cidade Guarapuava-PR, no ano de 2000, 2005 e 2012, publicadas pelo Jornal Diário de Guarapuava, meio de comunicação de grande circulação social local.

Com isso, objetiva-se contribuir com a problematização do papel da mídia na (des) informação e/ou compreensão do cidadão quanto aos desastres naturais, sobretudo, quando o foco midiático está mais na espetacularização dos acontecimentos do que no seu esclarecimento. 
DESASTRES NATURAIS VEICULADOS PELA MÍDIA: ANÁLISE DE CONTEÚDO DAS NOTÍCIAS DO JORNAL DIÁRIO DE GUARAPUAVA

\section{MATERIAIS E MÉTODOS}

A análise discursiva de jornais impressos, proposta neste artigo, tem como recorte especificamente, notícias sobre enchentes, inundações e alagamentos que ocasionalmente causaram desastres naturais na cidade de Guarapuava-PR. O periódico escolhido foi o jornal Diário de Guarapuava,impresso mais antigo, 13 anos de existência, e de maior circulação na cidade.

Considerando o período de circulação do jornal foram analisadas matérias a partir do ano de 2000. Destas, levando em consideração o seu conteúdo e a importância dada ao jornal para os desastres naturais (ou seja, quais delas foram manchete de capa), foram selecionadas sete matérias publicadas.

Quanto ao número selecionado, tratando-se de uma pesquisa qualitativa (com base em Minayo, 2001), a preocupação foi com a natureza das informações e sua saturação. Ou seja, a amostra foi definida na medida em que a reincidência das informações não permitiu ao pesquisador um dado novo. Assim, não é a quantidade das fontes dos dados, mas a recorrência da informação e seu conteúdo que orienta o total necessário à amostra.

Neste caso, após selecionar várias manchetes do jornal, escolheu-se àquelas que tratando do tema e sendo notícia de capa (maior importância dada ao evento pelo jornal, pelo espaço nele ocupado), trouxeram os elementos necessários à análise. Desta forma, foram selecionadas 07 matérias dos anos 2000, 2005 e 2012.

De acordo com a Rede Diários do Paraná, o Diário de Guarapuava conta com uma tiragem de 8.730 mil jornais de terça à sexta-feira e 9.380 mil nos sábados e domingos. É a maior tiragem entre todos os jornais da região, o que possibilita, consequentemente, que o jornal atinja um maior número de leitores.

Desta forma foram analisadas duas matérias do ano 2000, sendo estas as únicas produções jornalísticas do ano em questão que mostraram os eventos trabalhados nesta pesquisa. Outras duas notícias foram escolhidas, referente ao ano de 2005.Os jornais foram obtidos junto ao Centro de Documentação e Memória de Guarapuava (Cedoc). E outras quatro notícias, foram selecionadas do ano de 2012, sendo que as matérias desse ano foram localizadas no arquivo digital do Diário de 
DESASTRES NATURAIS VEICULADOS PELA MÍDIA: ANÁLISE DE CONTEÚDO DAS NOTÍCIAS DO JORNAL DIÁRIO DE GUARAPUAVA

Guarapuava, que contém apenas informativos dos últimos dois anos. As matérias selecionadas podem ser conferidas no Quadro 1.

\begin{tabular}{|c|c|c|}
\hline Data & Manchete (capa) & Dados da Edição \\
\hline $13 / 09 / 2000$ & Alagamentos atingem oito bairros & $\begin{array}{l}\text { Circulação Regional, quarta-feira, } 13 \text { de } \\
\text { setembro de } 2000 \text { / Ano II/ Edição } 452 . \\
\text { Capa12 (Segurança) }\end{array}$ \\
\hline $15 / 09 / 2000$ & Previsão de mais chuva na região & $\begin{array}{l}\text { Circulação Regional, sexta-feira, } 15 \text { de } \\
\text { setembro de } 2000 \text { / Ano II / Edição } 454 . \\
\text { Capa03 (Geral) }\end{array}$ \\
\hline $\begin{array}{c}22 \mathrm{e} \\
23 / 01 / 2005\end{array}$ & $\begin{array}{l}\text { Vila Carli: Alagamentos e falta de } \\
\text { saneamento mobilizam moradores }\end{array}$ & $\begin{array}{l}\text { Sábado e domingo, } 22 \text { e } 23 \text { de janeiro } \\
\text { de } 2005 \text { / Ano VI / Edição } 1532 . \\
\text { Capa03 (Geral) }\end{array}$ \\
\hline $06 / 10 / 2005$ & $\begin{array}{l}\text { Tempo: Chuva de granizo causa } \\
\text { muitos prejuízos }\end{array}$ & $\begin{array}{l}\text { Quinta-feira, } 06 \text { de outubro de } 2005 / \\
\text { Ano VI / Edição 1708. Capa03 (Geral) } \\
\end{array}$ \\
\hline $\begin{array}{c}14 \mathrm{e} \\
15 / 04 / 2012\end{array}$ & $\begin{array}{l}\text { Temporal causa alagamentos; Simepar } \\
\text { prevê chuvas fortes no fim de semana }\end{array}$ & $\begin{array}{l}\text { Guarapuava, sábado e domingo, } 14 \text { e } \\
15 \text { de abril de } 2012 \text { / Ano XIII / № } 3329 \\
\text { Edição Regional. } \\
\text { A5 (Cidade) }\end{array}$ \\
\hline $27 / 04 / 2012$ & Abril precipitado & $\begin{array}{l}\text { Guarapuava, sexta-feira, } 27 \text { de abril de } \\
2012 \text { / Ano XIII / № } 3338 \text { Edição } \\
\text { Regional. A4 e A5 (Cidade) }\end{array}$ \\
\hline 05/06/2012 & Crônica de um alagamento anunciado & $\begin{array}{l}\text { Guarapuava, terça-feira, } 05 \text { de junho de } \\
2012 \text { / Ano XIII / № 3364 Edição } \\
\text { Regional.A6 e A7 (Cidade) }\end{array}$ \\
\hline
\end{tabular}

Quadro 1: Diário de Guarapuava: notícias selecionadas (2000)

Organizado por NASCIMENTO, D. J. F. (2013).

Com a seleção destes materiais, optou-se pela metodologia da análise de conteúdo, proposto por Bardin (2010). Esta metodologia é um conjunto de técnicas que possibilitam a análise de comunicações (inclusive as de massa), podendo ser definida como: "Um conjunto de instrumentos metodológicos cada vez mais sutis em constante aperfeiçoamento que se aplicam a discursos (conteúdos e continentes) extremamente diversificados" (p. 11).

No caso específico desta pesquisa, a contribuição desta metodologia é que ela proporciona um recorte a nível semântico (por tema), podendo ser facilmente trazido para o trabalho, desde que se selecionem as ideias (ou enunciados) constituintes e descubram-se os núcleos de sentido que compõem a comunicação, cuja presença e frequência de aparição podem significar algo.

$\mathrm{Na}$ análise de conteúdo temática, nem todo o texto é levado em consideração, somente a dimensão das atitudes é que é cabível de avaliação. 
DESASTRES NATURAIS VEICULADOS PELA MÍDIA: ANÁLISE DE CONTEÚDO DAS NOTÍCIAS DO JORNAL DIÁRIO DE GUARAPUAVA

Assim, considerou-se a necessidade de utilização da análise de conteúdo, afim de identificar-se determinados elementos do jornal impresso, especificamente no que se refere às categorias 'causa' e 'consequência' dos desastres naturais. Outro ponto foi a análise das fontes (atores sociais) que aparecem nas matérias e 0 direcionamento das palavras (positivas ou negativas).

Nessa metodologia, um dos pontos que merece destaque é que as unidades do vocabulário podem ser classificadas em 'palavras plenas', definidas como aquelas portadoras de sentido (substantivo, adjetivo e verbo), e 'palavrasinstrumento', que são elementos funcionais de ligação (artigo, preposição, pronome, advérbio, etc.).

$\mathrm{Na}$ pesquisa, utilizou-se o processo de descrição dos conteúdos considerados passíveis e necessários de análise, seguido de inferências e, consequentemente, da interpretação dos dados.

Essa inferência "é o procedimento intermediário, que vem permitir a passagem, explícita e controlada" (BARDIN, 2010, p. 41), dos procedimentos de análise e de interpretação. Ressalta-se que 0 intuito foi 0 de analisar o que antecedeu na mensagem comunicacional e quais os efeitos dessa mensagem, sendo que, para isso, é necessária a inferência para que haja a ligação entre os dois pontos.

\section{RESULTADOS}

\section{A IMPRENSA E A PRODUÇÃO DO ESPETÁCULO}

Uma análise importante para o entendimento do processo de produção midiática, inclusive nos assuntos relacionados ao meio ambiente, está na obra de Andrade (2003). Segundo o autor, o debate ambiental é realizado "em um espaço dado a ensaios e performances, ou seja, um espetáculo" (p.13).No que tange ao espetáculo, o autor visualiza que em um discurso midiático, que promove a ausência de réplica (por parte do leitor), fica caracterizada a espetacularização, mas este fato que não é nocivo por si só, mas a partir do momento em que entram em cena os interesses da produção.

Mesmo debatendo as questões dos sistemas econômicos que dizem respeito à produção do espetáculo, Andrade (2003), não entra em conflito com a 
DESASTRES NATURAIS VEICULADOS PELA MÍDIA: ANÁLISE DE CONTEÚDO DAS NOTÍCIAS DO JORNAL DIÁRIO DE GUARAPUAVA

importância da mídia, pelo contrário, ele visualiza que os meios de comunicação são relevantes, a fim de que os problemas ambientais tornem-se parte do discurso público. Mas, para o autor, ainda é necessário que os atores sociais envolvidos com a temática aprendam a utilizar o espetáculo produzido pelas mídias em prol de uma intervenção qualificada nos rumos e resoluções dessas problemáticas, pois a espetacularização continuará.

Assim, visualiza-se que fatos e atores passam pelo processo de produção da notícia, que se faz por meio de um roteiro dramatizador, que inclui:

[...] (1) mostrar a desordem social com suas vítimas e seus perseguidores; (2) apelar para a reparação do mal, interpelando os responsáveis por este mundo; (3) anunciar a intervenção de um salvador, herói singular ou coletivo com o qual cada um pode identificar-se. (CHARAUDEAU, 2010, p. 254)

Para Charaudeau (2010), ao serem apresentadas as notícias por meio de roteiro dramatizador, o leitor não é mais tratado como cidadão e sim como expectador. A notícia surge como a prova da realidade dos fatos e, consequentemente, acrescentando algo para a apreciação da opinião pública. $O$ autor supracitado, ainda, destaca que a mídia possui uma influência através do fazer saber, do fazer pensar e do fazer sentir. Essa influência ocorre indiretamente, por meio das instâncias de produção e de recepção, onde a primeira age como testemunha do mundo e também como interpelador do público-cidadão e a segunda instância possui um papel reativo de espelho deformante.

Essa relação entre as instâncias ocorre sem troca, pois a mídia repassa sua informação para consumo e o leitor recebe e reinterpreta à sua maneira, sem poder interpelar a instância de produção.

Dessa forma, a partir da noção de produção do "espetáculo midiático", está preparado o pano de fundo para que as análises aqui apresentadas ganhem sentido.

\section{OS DESASTRES NATURAIS: PROCESSOS DECORRENTES (ENCHENTES, INUNDAÇÕES E ALAGAMENTOS)}

Como citado anteriormente, o interesse é verificar como a mídia produz o discurso sobre os desastres naturais. Esta escolha não é arbitrária, mas sim, pela 
DESASTRES NATURAIS VEICULADOS PELA MÍDIA: ANÁLISE DE CONTEÚDO DAS NOTÍCIAS DO JORNAL DIÁRIO DE GUARAPUAVA

urgência na abordagem desse tema que tem provocado comprometimentos ambientais e sociais cada vez mais intensos, até mesmo em áreas que não são grandes centros, onde tradicionalmente a aglomeração humana em áreas de risco é, nas circunstâncias dos desastres, a combinação de muitos prejuízos econômicos e sociais.

Mas o mais grave é que embora haja reincidências com desastres cada vez mais frequentes e em mais lugares, pouco se tem visto de ações efetivas para evitar as tragédias.

A mídia tem tido um papel importante na divulgação e denúncia dos processos que concorrem para a ocorrência dos desastres, porém, os diferentes interesses e conotações que esta ganha na sociedade atual, nem sempre garante que ela seja uma aliada na formação crítica do pensamento do cidadão e, portanto, na contribuição da solução destes problemas.

Kobiyama, et al (2006), explica que a origem desses fenômenos naturais podem estar relacionados com as dinâmicas interna ou externa do planeta, sendo que as de origem interna são os causados pela movimentação de placas tectônicas, que têm reflexo na superfície do planeta (terremotos, tsunamis, vulcanismo, entre outros), e as dinâmicas de origem externa são oriundas da dinâmica atmosférica (tempestades, tornados, secas, inundações, etc).

Mafra e Mazzola (2007) lembram que, no Brasil, não existe tendência para a ocorrência de fenômenos de dinâmica interna. Tominaga (2009) concorda com os autores e acrescenta que, no país, estes fenômenos de dinâmica interna caracterizam-se apenas pela ocorrência de fracos tremores. Para a autora, são os fenômenos de dinâmica externa os principais causadores de desastres naturais no Brasil, e estão normalmente associados a eventos pluviométricos intensos e prolongados.

A terminologia desastres naturais, indica 'eventos extremos' em locais onde se concentram seres humanos, gerando impactos socioeconômicos significativos. Também é importante ressaltar que embora seja possível compreender a origem do fenômeno no seu aspecto natural, não se pode naturalizar o desastre que, via de regra, tem razões antrópicas. Sobre isso, Vestena (2008) afirma que: "os desastres naturais estão diretamente associados às características físicas do meio ambiente e 
DESASTRES NATURAIS VEICULADOS PELA MÍDIA: ANÁLISE DE CONTEÚDO DAS NOTÍCIAS DO JORNAL DIÁRIO DE GUARAPUAVA

aos condicionantes antrópicos, principalmente, ao modo de uso e ocupação do solo" (p. 152).

Dessa forma, considerando que o desastre se caracteriza em áreas habitadas,podemos afirmar que a não observância das características físicas do ambiente associada à ausência de medidas preventivas são elementos potencializadores dos desastres naturais decorrentes de inundações e alagamentos.

Deste modo, conforme ressalta Marcelino (2008), as intervenções humanas podem intensificar e/ou agravar um desastre natural, ou seja, indicam o estado de vulnerabilidade local, mas não podem ser consideradas as causas de um desastre natural.

Já, Coelho Netto e Avelar (2007) destacam que o elemento água é importante para os processos que condicionam a vida no planeta, e as interferências humanas sobre esse ciclo ampliam os desastres naturais. Dessa forma, no caso dos desastres naturais decorrentes de processos hidrológicos e pluviométricos, a importância do ciclo hidrológico é evidente.

Neste ciclo da água, muitos conceitos são dados como sinônimos, embora, possuam natureza diferente, como aqueles que compõem o mesmo processo. Quanto aos conceitos de enchente, inundação e/ou alagamento, além serem processos intensificados no espaço urbano, via de regra, estão presentes na mídia como sinônimos. Sua associação, muitas vezes, serve mais para confundir do que para esclarecer ao leitor.

No que diz respeito às terminologias, destaca-se que enchente significa "ocupar o vão, a capacidade ou a superfície de; tornar cheio ou repleto" (GOERL; KOBIYAMA, 2005, p. 3). Os autores explicam que, após o processo de enchente, o que ocorre é uma inundação, citando:

As palavras cheia e enchente têm como origem o verbo encher, do Latim implere, que significa: ocupar o vão, a capacidade ou a superfície de; e tornar cheio ou repleto. Quando as águas do rio elevam-se até a altura de suas margens, contudo, sem transbordar nas áreas adjacentes, é correto dizer que ocorre uma enchente. A partir do momento em que as águas transbordam, ocorre uma inundação. $(2005$, p. 3) 
DESASTRES NATURAIS VEICULADOS PELA MÍDIA: ANÁLISE DE CONTEÚDO DAS NOTÍCIAS DO JORNAL DIÁRIO DE GUARAPUAVA

A partir do momento em que ocorre o transbordamento, vários são os tipos de inundações que podem ocorrer, sendo que os tipos mais comuns são inundações costeiras, graduais e bruscas, como indicam os autores supracitados.

Neste trabalho, interessa as inundações graduais e as bruscas, sendo que as graduais ocorrem quando o transbordamento se manifesta de forma lenta $e$ gradativa, não sendo tão violenta, mas atingindo uma grande extensão. A inundação brusca, como o nome já diz, ocorre rapidamente, causando grandes desastres nos locais onde acontecem, por não haver tempo hábil para que se faça um alerta sobre o evento (GOERL; KOBIYAMA, 2005).

Oliveira (2011) acrescenta que as enchentes devem ser consideradas um fenômeno natural que compõe a dinâmica natural do curso fluvial. Ela ocorre quando o leito de vazante é extrapolado, fazendo com que as margens plenas sejam preenchidas pelo débito fluvial. Já a inundação é o momento em que um fluxo relativamente alto, ultrapassa a capacidade do canal, com o extravasamento das águas para as planícies adjacentes, em virtude da quantidade de água ser superior à capacidade do leito. Estas situações podem ser mais bem compreendidas na Figura 1.

A partir da Figura 1, pode-se observar a diferença entre inundação e enchente. A inundação ocorre em áreas correspondentes à planície de inundação do rio. Enquanto as enchentes ocupam apenas o leito maior e menor do mesmo.

Já os alagamentos, segundo Souza (2004), "ocorrem em áreas distantes dos canais, em terrenos com ocupação antrópica e baixo coeficiente de escoamento superficial" (p. 232) e com fluxos de baixa velocidade. Na Figura 1, pode-se comparar os três fenômenos. 


\title{
$\checkmark$ Enchente, inundação e alagamento;
}

\author{
SÃO PREOCUPANTES PORQUE \\ CAUSAM EFEITOS IMEDIATOS (DIRETOS) E EFEITOS POSTERIORES (INDIRETOS \\ À SAÚDE HUMANA;
}

Inundação é o

Enchente ou cheia é o aumento temporário do nível d'água no canal de drenagem devido ao aumento da vazão*, atingindo a cota máxima do canal, porém, sem transbordamento.

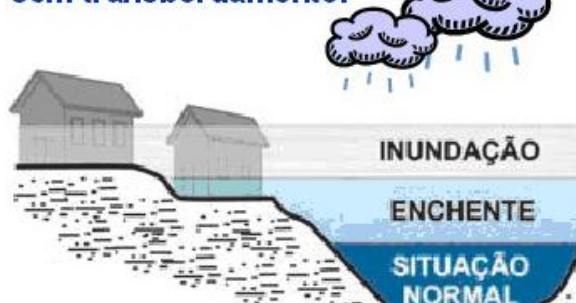$$
=
$$
de várzea) transbordamento das águas de um canal de drenagem, atingindo as áreas marginais (planície de inundação ou área

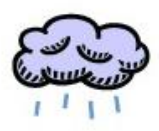

Alagamento é o acúmulo de água nas ruas e nos perímetros urbanos, por problemas de drenagem

Figura 1: Enchente, inundação e alagamento. Fonte: Defesa Civil de São Bernardo do Campo'.

Nota-se então, que o alagamento configura-se em um acúmulo momentâneo de águas em um determinado local no meio urbano, na maioria das vezes, por problemas no sistema de drenagem, tais como: canalização, retificação, estrangulamento da rede pluvial (artificial), impermeabilização do solo. Portanto, embora os processos de enchente, inundação e alagamento estejam interligados, eles não são sinônimos como no "senso comum" possa se considerar.

Porém, é fato que a urbanização descontrolada e sem planejamento intensificam os processos que potencializam a ocorrência de catástrofes. A consequência deles é de toda ordem, óbitos, desabrigados, desalojados, feridos, etc. Há, portanto, necessidade de aprimorar os sistemas de gestão ambiental, e, nas cidades investir no planejamento e na capacitação de pessoal, seja para atendimento as pessoas atingidas pelos eventos, seja para elaborar propostas de mitigação e prevenção das catástrofes, o que implica em melhoria em infraestrutura, mas também, na formação de pessoas e na educação ambiental.

1 Disponível em: http://dcsbcsp.blogspot.com.br/2011/06/enchente-inundacao-oualagamento.html. Acessado em: 23/07/2012. 
DESASTRES NATURAIS VEICULADOS PELA MÍDIA: ANÁLISE DE CONTEÚDO DAS NOTÍCIAS DO JORNAL DIÁRIO DE GUARAPUAVA

\section{ANÁLISE DE CONTEÚDO DAS MATÉRIAS JORNALÍSTICAS DO DIÁRIO DE GUARAPUAVA: OS DESASTRES NATURAIS, ORIGEM E CONSEQUÊNCIAS.}

Para a análise de conteúdo a que se propõe este trabalho, as matérias serão citadas da seguinte forma: 2000-1 (Edição 452, de 13/09/2000); 2000-2 (Edição 454, de 15/09/2000); 2005-1 (Edição 1532, de 22 e 23/01/2005); 2005-2 (Edição 1708, de 06/10/2005); 2012-1 (Edição 3329, de 14 e 15/04/2012); 2012-2 (Edição 3338, de 27/04/2012) e 2012-3 (Edição 3364, de 05/06/2012).

Como ilustração, destaca-se o recorte de trecho edição 2012-1 (Figura 2), onde se demonstra a forma de análise do conteúdo.

\section{Temporal provoca danos; Simepar prevê mais chuvas e ventos fortes no fim de semana}
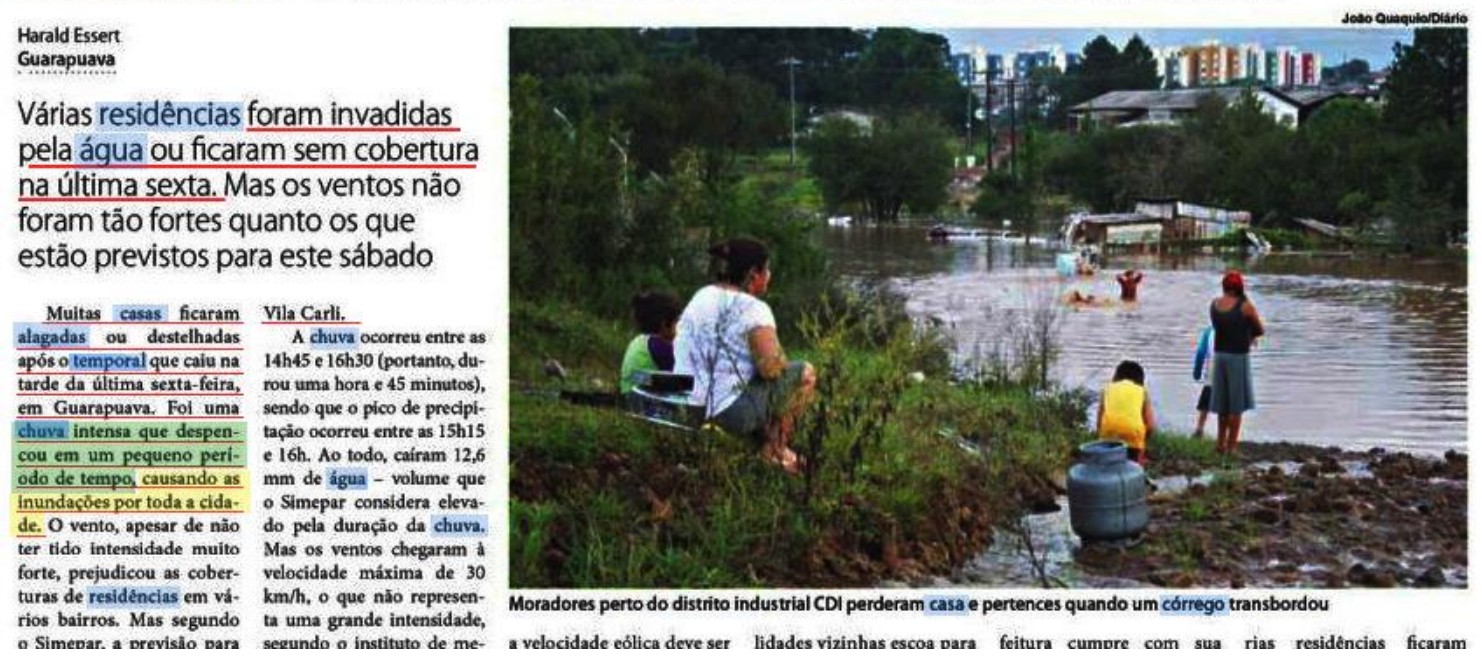

Figura 2: Modelo da análise do conteúdo. Recorte de trecho edição 2012-1.

Organizado por NASCIMENTO, D. J. F. (2011).

$\mathrm{Na}$ imagem (Figura 2), está o exemplo dos procedimentos de extração dos conteúdos realizados para a análise da matéria jornalística. No texto, selecionou-se, em verde, aquilo que aparece como a causa do problema; em amarelo a consequência; e, em azul, as palavras plenas (portadoras de sentido). Em vermelho, foram sublinhadas as frases que mostram o direcionamento da matéria.

A partir do trabalho realizado em todas as matérias selecionadas, iniciou-se pela categorização das 'causas' e 'consequências' dos desastres naturais, conforme a Tabela 1. As causas e as consequências foram explicitadas conforme estão 
DESASTRES NATURAIS VEICULADOS PELA MÍDIA: ANÁLISE DE CONTEÚDO DAS NOTÍCIAS DO JORNAL DIÁRIO DE GUARAPUAVA

citadas nas páginas do Diário de Guarapuava, pois a análise aqui sugerida necessita dessa informação do ponto de vista do periódico.

Tabela 1: Categorização das 'causas' e 'consequências'

\begin{tabular}{|c|c|c|}
\hline \multirow[b]{2}{*}{ Matéria } & \multicolumn{2}{|c|}{ CATEGORIAS } \\
\hline & Causa & $\begin{array}{c}\text { Consequência (palavras e frases } \\
\text { enunciadas no jornal) }\end{array}$ \\
\hline $2000-1$ & Chuva & $\begin{array}{l}\text { - Alagamentos } \\
\text { - Inundações } \\
\text { - Água tomava conta de terrenos }\end{array}$ \\
\hline $2000-2$ & Chuva forte & $\begin{array}{l}\text { - Prejuízos para os moradores } \\
\text { - Pessoas desabrigadas }\end{array}$ \\
\hline $2005-1$ & $\begin{array}{l}\text { Chuva, riachos e construção de um } \\
\text { canal de tubulado }\end{array}$ & $\begin{array}{l}\text { - Inundações } \\
\text { - Enchentes } \\
\text { - Piora da situação }\end{array}$ \\
\hline $2005-2$ & Temporal & $\begin{array}{l}\text { - Prejuízos aos guarapuavanos } \\
\text { - moradores sem poder sair de casa }\end{array}$ \\
\hline $2012-1$ & $\begin{array}{l}\text { Chuva intensa em um pequeno período } \\
\text { de tempo }\end{array}$ & - Inundações por toda a cidade \\
\hline $2012-2$ & Chuva intensa & $\begin{array}{l}\text { - Alagamentos e transtornos em } \\
\text { diversos bairros }\end{array}$ \\
\hline $2012-3$ & Chuva forte & $\begin{array}{l}\text { - Casas alagadas } \\
\text { - Prejuízos }\end{array}$ \\
\hline
\end{tabular}

Organizado por: NASCIMENTO, D. J. F. (2012).

Com essa primeira análise, visualiza-se alguns dos principais elementos do conteúdo das matérias do jornal analisado. De acordo com este meio de comunicação, a chuva é a principal causadora dos desastres naturais e traz uma série de consequências negativas para sociedade.

Como a chuva antecedeu o acontecimento e o resultado foram os desastres, podemos inferir que está evidente o discurso naturalista do meio de comunicação, pois são deixados de lado às interferências humanas (urbana) e os problemas socioeconômicos que potencializam e aceleram os desastres.

Em um segundo momento, conforme sugere Bardin (2010), considerou-se a necessidade de avaliar as palavras portadoras de sentido, ou palavras plenas, como define a autora. A Tabela 2 apresenta a relação das palavras plenas consideradas importantes para a temática desta pesquisa. 
DESASTRES NATURAIS VEICULADOS PELA MÍDIA: ANÁLISE DE CONTEÚDO DAS NOTÍCIAS DO JORNAL DIÁRIO DE GUARAPUAVA

Tabela 2: Palavras plenas

\begin{tabular}{|c|c|c|c|c|c|c|c|c|}
\hline \multirow{2}{*}{ Termo } & \multicolumn{8}{|c|}{ Ocorrências } \\
\hline & $2000-1$ & $2000-2$ & $2005-1$ & $2005-2$ & $2012-1$ & $2012-2$ & $2012-3$ & Total \\
\hline Residência/Casa & 8 & 1 & 7 & 7 & 12 & 7 & 10 & 52 \\
\hline Chuva & 4 & 6 & 5 & 4 & 12 & 12 & 6 & 49 \\
\hline Moradores & 1 & 1 & 9 & 3 & 5 & 4 & 10 & 33 \\
\hline Água & 3 & 1 & 5 & 1 & 7 & 5 & 7 & 29 \\
\hline Alagamento & 2 & 1 & 5 & 1 & 3 & 6 & 4 & 22 \\
\hline Córrego/Riacho/Rio & 1 & - & 6 & 2 & 1 & 5 & 7 & 22 \\
\hline Problema & 1 & - & 2 & 1 & 1 & 1 & 5 & 11 \\
\hline Prejuízo/Danos & - & 1 & - & 2 & 3 & 2 & 1 & 9 \\
\hline Prefeitura & - & - & 3 & - & 2 & 1 & 2 & 8 \\
\hline Risco & - & 2 & - & 1 & 1 & 3 & 1 & 8 \\
\hline Bombeiros & 1 & - & - & - & 2 & 3 & 1 & 7 \\
\hline Infraestrutura/Obras & - & - & 3 & - & - & - & 4 & 7 \\
\hline Melhorias & - & - & 7 & - & - & - & - & 7 \\
\hline Transbordamento & - & - & - & 1 & 1 & 3 & 2 & 7 \\
\hline Inundação & 1 & - & - & - & 5 & - & - & 6 \\
\hline Defesa Civil & - & 2 & - & 1 & - & 2 & - & 5 \\
\hline SIMEPAR & - & - & - & - & 2 & 2 & 1 & 5 \\
\hline Tempestade & - & 2 & - & - & 3 & - & - & 5 \\
\hline Temporal & - & - & - & 2 & 2 & - & - & 4 \\
\hline Transtornos & - & - & - & - & - & 2 & 2 & 4 \\
\hline Desabrigado/Desalojado & - & 1 & - & - & - & 2 & - & 3 \\
\hline Enchente & - & - & 1 & 1 & - & - & 1 & 3 \\
\hline Sofrimento & - & - & 2 & - & - & 1 & - & 3 \\
\hline Sujeira/Lixo & 1 & - & - & 2 & - & - & - & 3 \\
\hline
\end{tabular}

Organizado por: NASCIMENTO, D. J. F. (2012).

A contabilização das palavras plenas mostra que o conteúdo das matérias opta por palavras que remetem aos problemas que afetam os moradores e também as residências das localidades atingidas por desastres naturais. A grande ocorrência da palavra chuva também é um ponto interessante, tendo em vista que o termo é atrelado ao "vilão" do problema, além disso, está amplamente ligado nas notícias, à simbologia atribuída à água como uma das causadoras dos problemas.

É interessante como a análise mostra que o informativo apresenta grande incidência de referências às palavras córrego, riacho e rio (como sinônimos), mas deixa de lado os problemas de ocupação em áreas de risco, mesmo que, muitas vezes, seja citado o termo "risco". 
Tendo em vista que as palavras enchente, inundação e alagamento são utilizados como sinônimos, evitando que o meio de comunicação recorra em repetições, caso fosse utilizado apenas um dos termos, também é notada a predisposição do jornal pela palavra alagamento, ao invés de enchente ou inundação.

Destaca-se, ainda, que os problemas de infraestrutura são pouco percebidos nas notícias, pois são minimamente citados, remetendo à hipótese de que a naturalização é mais apta ao discurso jornalístico, pois não existem formas de contestar esses "problemas naturais".

No Gráfico 1, pode-se observar a incidência das palavras plenas nas notícias analisadas.

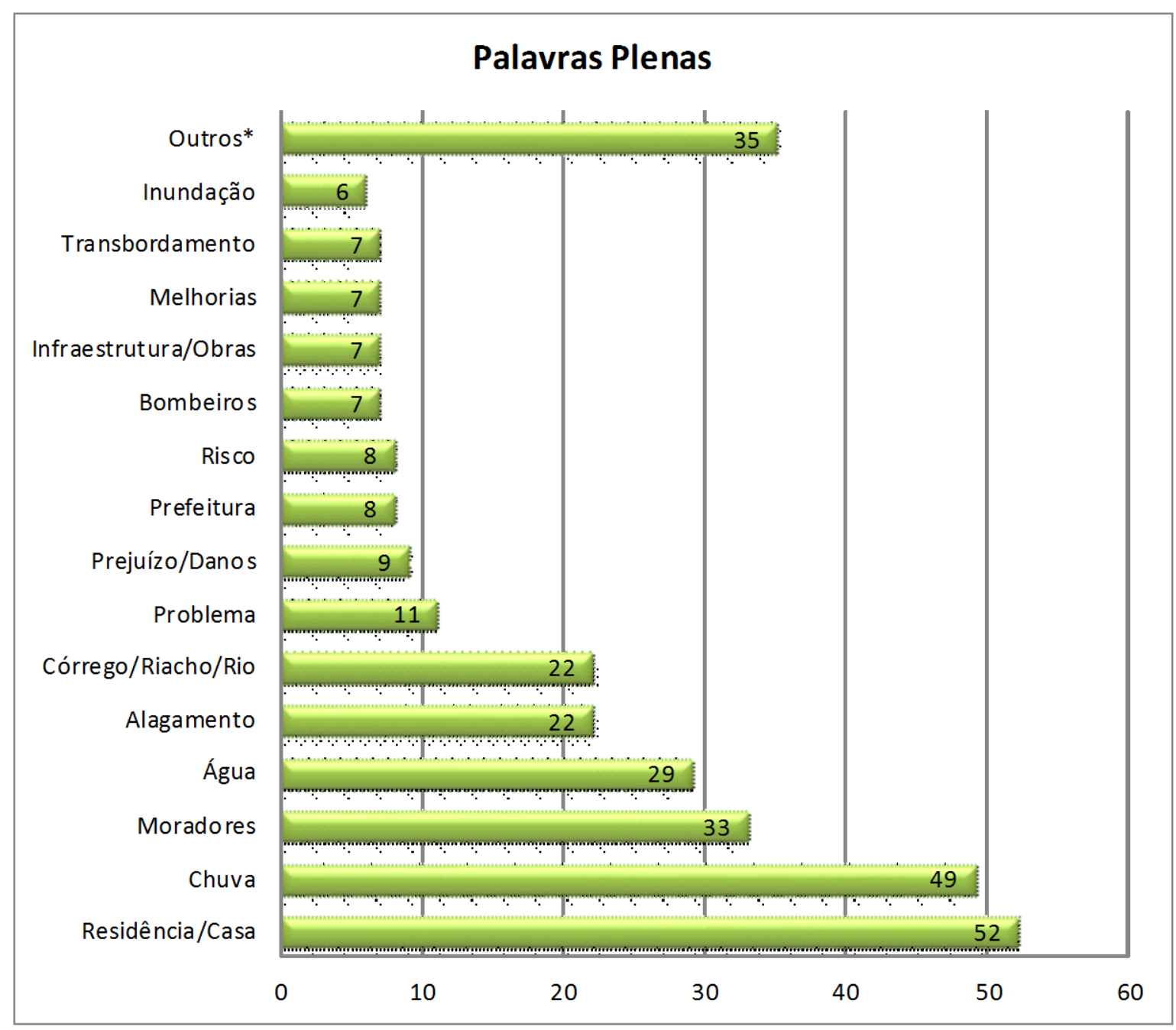

*A palavra "Outros" se refere a outras palavras plenas citadas poucas vezes nas matérias.

Gráfico 1: Principais palavras plenas. Organizado por: NASCIMENTO, D. J. F. (2012). 
DESASTRES NATURAIS VEICULADOS PELA MÍDIA: ANÁLISE DE CONTEÚDO DAS NOTÍCIAS DO JORNAL DIÁRIO DE GUARAPUAVA

Cabe ainda destacar uma última análise das notícias, que diz respeito à classificação das fontes. Englobando todas as matérias, nota-se que, o Diário de Guarapuava, tem preferência por utilização de vítimas para compor com seu discurso. Ao todo, foram 19 vítimas afetadas pelo desastre natural e citadas nas sete matérias. Neste aspecto, nas mesmas notícias foram contabilizadas sete aparições de especialistas, estudiosos do assunto e, portanto, avalistas do conteúdo apresentada, quatro de representantes do governo, técnicos da prefeitura, corpo de bombeiros e membro da defesa civil e apenas uma pessoa da sociedade civil externa ao problema, pessoa que não foi afetada pelo desastre, mas opinou sobre o evento.

Esses números confirmam que o meio de comunicação opta pela utilização de vítimas, seja para respaldar seu discurso ou para criar a dramatização do fato, fazendo com que os leitores se identifiquem com aqueles que estão sofrendo.

Quanto ao direcionamento das palavras, nota-se que, por um lado, aparecem inúmeros termos com direcionamento positivo (como as residências/casas e os moradores), por outro, surgem inúmeras palavras com simbologia que atribui valor negativo (chuva, água, alagamento, etc.). Essas direções, favoráveis ou não, ajudam o meio de comunicação a fixar seu discurso. Por exemplo, nas matérias sobre desastres naturais, o jornal apresenta a chuva e a água como as vilãs, pois são elas que estão "prejudicando" a vida das pessoas. Mas, se o cunho da notícia fosse a degradação do meio ambiente, provavelmente, essas palavras teriam conotação positiva.

Conclui-se que o discurso jornalístico do Diário de Guarapuava molda-se ao conteúdo que é apresentado nas páginas do informativo. O interdiscurso e seus elementos são percebidos nas linhas e também nos conteúdos que compõem o periódico como mídia de massa. O efeito dessas notícias (mensagens), apresentando uma visão naturalista dos desastres naturais, tem reflexo na sociedade, pois se cria o senso comum de que o fenômeno é exclusivamente natural, olvidando a ausência de planejamento, associada à omissão de diferentes atores sociais (estado, incorporadores imobiliários, proprietários fundiários, etc.) como parte componente do processo. 
DESASTRES NATURAIS VEICULADOS PELA MÍDIA: ANÁLISE DE CONTEÚDO DAS NOTÍCIAS DO JORNAL DIÁRIO DE GUARAPUAVA

Deste modo, verifica-se que de fato a mídia atua na popularização do debate sobre os problemas ambientais, porém, é pouco eficiente na divulgação de suas implicações. As explicações nos jornais, além de apresentar equívocos conceituais sobre alagamento, inundação e enchente naturalizam estes processos, facultando ao leitor, a possibilidade de compreender a multidimensionalidade imbricada na origem e consequências dos desastres naturais deles decorrentes, as quais integram em fatores físicos, mas também econômicos, sociais e políticos.

\section{CONSIDERAÇÕES FINAIS}

A abordagem proposta não tem 0 intuito de condenar o meio de comunicação analisado, mas avaliar o discurso da mídia sobre o meio ambiente ao afetar a vida das pessoas. Mesmo porque, considera-se importante o papel do jornal impresso, neste caso, do Diário de Guarapuava, ao trazer para os debates do espaço público assuntos que dizem respeito aos problemas enfrentados na cidade. Porém, nesta pesquisa, é objeto de crítica à priorização de uma vertente da análise do processo em detrimento de outros.

No que tange aos acontecimentos que surgem da interação da sociedade com o meio ambiente, nota-se que esses assuntos não fogem do foco midiático, pelo contrário, cada vez mais ganham espaço nos campos destinados à produção dos meios de comunicação de massa.

Mesmo que o foco seja uma produção que busca apreender o consumidor deste meio de comunicação por meio de uma produção totalmente pensada, não se pode negar a importância da mídia para que os debates sobre o meio e a sociedade, suas dinâmicas e interações, eclodam no espaço público e fecundem uma opinião pública crivada de cidadania e de visão realmente ambientalista.

Entretanto, a análise das notícias do Diário de Guarapuava mostrou que a mídia produz seu espetáculo também sobre os acontecimentos que remetem aos desastres naturais. Como a produção ganha ares de dramatização, a matéria tende a criar leitores que se identificam com aqueles que são atingidos pelos desastres, se sentindo parte da sociedade que foi afetada, mesmo que nunca tenham tido problema com alagamentos ou qualquer outro fenômeno desse tipo. Porém, ao 
DESASTRES NATURAIS VEICULADOS PELA MÍDIA: ANÁLISE DE CONTEÚDO DAS NOTÍCIAS DO JORNAL DIÁRIO DE GUARAPUAVA

remeter a causa à chuva, esvazia a possibilidade de discussão e de análise critica da questão, banalizando o problema.

Nesse sentido, a forma com que a natureza é tratada, especificamente nas matérias sobre os desastres naturais, sendo a chuva aferida como a única vilã destes processos, torna-se um empecilho para os embates (e debates) que envolvem as interações sociedade-natureza.

Observou-se que esse processo que naturaliza os acontecimentos, deixando de lado os problemas sociais, como a urbanização feita sem planejamento e as ocupações de áreas que deveriam ser preservadas, é algo que favorece a produção midiática, pois é mais fácil que a culpa seja atribuída em algo que não pode ser questionado, do que buscar equacionar os problemas onde os agravantes são a inoperância do sistema social, econômico e político vigente. Além disso, essa naturalização passa pelo crivo da produção para as massas, que prevê matérias de fácil entendimento e aceitação por todos, o que resulta na simplificação dos conteúdos, a fim de criar o senso comum sobre determinados elementos e acontecimentos.

É por isso que torna-se mais prático para o meio de comunicação tratar de forma simplória e como sinônimos termos como alagamento, inundação e enchente, pois, provavelmente, não seria interessante do ponto de vista midiático, definir técnica e cientificamente cada um dos termos.

Porém, tem-se que além da questão dos termos equivocados, um papel fundamental da mídia, que muitas vezes é pouco explorado, está no fato de demonstrar a implicação ambiental, política, cultural e social do problema, sendo uma ferramenta a favor do cidadão. Talvez se este enfoque fosse destacado, o leitor tivesse proveito quanto à formação crítica sobre este tema e outros que afetam a sociedade.

Enfim, embora seja premente a promoção da cidadania, e os meios de comunicação de massa sejam peças fundamentais na construção do entendimento das questões ambientais e de sua divulgação, ainda há muito que ser feito. Embora o uso deste veículo tenha crescido no sentido de sensibilizar a população, o foco da "espetacularização" ainda tem um espaço muito maior do que o do comprometimento com a sociedade e com a informação crítica. 
DESASTRES NATURAIS VEICULADOS PELA MÍDIA: ANÁLISE DE CONTEÚDO DAS NOTÍCIAS DO JORNAL DIÁRIO DE GUARAPUAVA

\section{REFERÊNCIAS}

ANDRADE, T. Ecológicas manhãs de sábado: o espetáculo da natureza na televisão brasileira. São Paulo: Annablume: Fapesp, 2003.

BARDIN, L. Análise de conteúdo. Lisboa: Edições 70, 2010.

BRASIL. Ministério da Integração Nacional. Secretaria Nacional de Defesa Civil. Centro Nacional de Gerenciamento de Riscos e Desastres. Anuário brasileiro de desastres naturais: 2012 / Centro Nacional de Gerenciamento de Riscos e Desastres. - Brasília: CENAD, 84 p. 2012.

CHARAUDEAU, P. Discurso das Mídias. Tradução: Angela Côrrea. $2^{a}$ ed. São Paulo: Contexto, 2010.

COELHO NETTO, A.L.; AVELAR, A.S. O uso da terra e a dinâmica hidrológica. In: SANTOS, R. F. (org.). Vulnerabilidade Ambiental. Brasília: Ministério do Meio Ambiente, p. 59-73. 2007.

GOERL, R.F.; KOBIYAMA, M. Considerações sobre as inundações no Brasil. In: Laboratório de Hidrologia da Universidade Federal de Santa Catarina - UFSC. 2005. Disponível em: <http://www.labhidro.ufsc.br/Artigos/ABRH2005 inundacoes.pdf >. Acesso em: 30/07/2012.

KOBIYAMA, M.; et al. Prevenção de desastres naturais: conceitos básicos. Florianópolis: Ed. Organic Trading, 2006.

MAFRA, C.; MAZZOLA, M. As razões dos desastres em território brasileiro. In: SANTOS, R.F. (org.). Vulnerabilidade Ambiental. Brasília: Ministério do Meio Ambiente, p. 10-12. 2007.

MARCELINO, E.V. Desastres naturais e geotecnologias: conceitos básicos. Santa Maria: Ministério da Ciência e Tecnologia (Instituto Nacional de Pesquisas Espaciais), 2008.

MINAYO, M.C.S. (org). Pesquisa social: teoria, método e criatividade. Petrópolis/RJ: Vozes, 2001.

NASCIMENTO, D.J.F. Análise dos desastres noticiados na mídia por meio do jornal impresso de Guarapuava-PR. Guarapuava: Unicentro. Dissertação de Mestrado. 2012. 
OLIVEIRA, É.D. Impactos da urbanização na geometria hidráulica de canais fluviais da bacia hidrográfica do Rio Cascavel. Dissertação de Mestrado. Universidade Estadual do Centro-Oeste - Unicentro. Guarapuava, 2011.

SOUZA, C.R.G. Risco a inundações, enchentes e alagamentos em regiões costeiras. In: Anais do Simpósio Brasileiro de Desastres Naturais, 2004, Florianópolis. Anais. Florianópolis: GEDN/UFSC, p. 231-247. 2004.

TOMINAGA, L.K. Desastres Naturais: Por que ocorrem? In: TOMINAGA, L.K.; SANTORO, J.; AMARAL, R.A. (orgs). Desastres Naturais: conhecer para prevenir. São Paulo: Instituto Geológico, p. 12-23. 2009.

VESTENA, L.R. A importância da hidrologia na prevenção e mitigação de desastres naturais. In: Revista Ambiência. Guarapuava: Editora Unicentro, p. 151162. 2008. 